\title{
Raman spectroscopic identification of size-selected airborne particles for quantitative exposure assessment
}

\author{
Brian Steer ${ }^{1,2^{*}}$, Boris Gorbunov ${ }^{1}$, Mark C. Price ${ }^{2}$, Adrian Podoleanu ${ }^{2}$ \\ ${ }^{I}$ Naneum Ltd., Canterbury Innovation Centre, University Road, Canterbury, Kent, CT2 7FG, \\ $U K$ \\ ${ }^{2}$ School of Physical Sciences, University of Kent, Canterbury, Kent, CT2 7NH, UK
}

\begin{abstract}
In this paper we present a method for the quantification of chemically distinguished airborne particulate matter, required for health risk assessment. Rather than simply detecting chemical compounds in a sample, we demonstrate an approach for the quantification of exposure to airborne particles and nanomaterials. In line with increasing concerns over the proliferation of engineered particles we consider detection of synthetically produced $\mathrm{ZnO}$ crystals. A multi-stage approach is presented whereby the particles are first aerodynamically size segregated from a lab-generated single component aerosol in an impaction sampler. These size fractionated samples are subsequently analysed by Raman spectroscopy. Imaging analysis is applied to Raman spatial maps to provide chemically specific quantification of airborne exposure against background which is critical for health risk evaluation of exposure to airborne particles. Here we present a first proof-of-concept study of the methodology utilising particles in the $2-4 \mu \mathrm{m}$ aerodynamic diameter range to allow for validation of the approach by comparison to optical microscopy. The results show that the combination of these techniques provides independent size and chemical discrimination of particles. Thereby a method is provided to allow quantitative and chemically distinguished measurements of aerosol concentrations separated into exposure relevant size fractions.
\end{abstract}

Keywords: Zinc oxide; Aerodynamic equivalent diameter; Raman spatial mapping; Aerosols; Particle characterization; Quantitative exposure measurement.

\footnotetext{
* Corresponding author.

Tel: +44 1227811705

E-mail address: bs234@kent.ac.uk
} 


\section{Introduction}

There is a growing demand for devices that provide both size resolved information and chemical identification of aerosol particles (Kuhlbusch et al., 2011, Maynard \& Aitken, 2007). Size resolved information is critical in the evaluation of deposition of particles in the lungs (e.g. Oberdörster et al., 2005). This is required, for example, to address the health risks associated with exposure to airborne nanoparticles at working places and residential areas (Donaldson et al., 2000; Maynard \& Kuempel, 2005; Pope et al., 2006; Yang et al., 2008). Recently there has been a proliferation of engineered nanoparticles (ENP) in various products and industrial processes (Meyer et al., 2009). Due to the uncertain health risks associated with these materials (Simeonova et al., 2009), it is a matter of pressing urgency to develop a technique that can detect and quantify ENP selectively in size resolved samples. It is of particular importance to develop methods to distinguish these particles of interest from a potentially much higher, but more benign, background aerosol concentration (Kuhlbusch et al., 2011; Ono-Ogasawara et al., 2009). Much work has been carried out previously on identifying the chemical composition of sampled aerosol particles using a wide range of different techniques (e.g. see reviews by Chow, 1995; Maynard, 2000; McMurry, 2000; Matti Maricq, 2007; and Chow et al., 2008). While such studies have been invaluable in helping to identify sources and compositions of aerosols, they do not provide a quantitative exposure metric. Such a metric would allow for either a comparison to be made to measured responses, or assessments of risks to be carried out if a suitable response correlation is understood.

We employ a two stage technique for characterizing ENP and other aerosols. First, aerosol particles are sampled and size segregated from the atmosphere utilizing a size resolved sampler. Here we use a 'Nano-ID ${ }^{\circledR}$ Select' (Gorbunov et al., 2009) which is commercially available from Naneum (www.naneum.com). A primary benefit of this sampler is that it characterizes particles according to their aerodynamic equivalent diameter. This is a critical parameter as it determines the deposition efficiency of particles in the lungs and respiratory tract and is crucial for understanding the potential health risks of aerosol particles (Kreyling et al., 2006). It is also worth noting that while freshly generated ENP may have primary particle sizes in the order of $20 \mathrm{~nm}$, the material will quickly agglomerate in the air up to submicron sized particles (e.g. $\sim 100-300 \mathrm{~nm}$ ) which can survive much longer in the air due to their lower diffusion mobility (Eggersdorfer and Pratsinis, 2014). The second stage is to analyse the size ranges of interest with Raman spectroscopy to provide chemically sensitive detection of particles. Finally, with consideration of the sampled volume, a quantitative 
analysis is carried out which allows for the absolute determination of concentrations of a particular species in the air. This final step is critical for providing a meaningful exposure assessment, and is the key benefit of this approach compared to previous studies.

Micro-Raman spectroscopy (Huong \& Verma, 1990) provides sensitive detection of chemical traces in a dominant background aerosol matrix. The same technique is also able to distinguish small deposits from a substrate material and has seen increasing application to nanomaterials (Gouadec \& Colomban, 2007). Other techniques have been used for the identification of aerosol particles including; various mass spectrometry techniques (Prather et al., 1994; Koch et al., 2002; Horn \& Günther, 2003; Mouli et al., 2006; Nizkorodov et al. 2011; Laskin et al., 2013; O'Brien et al., 2013), energy-dispersive X-ray analysis (EDX) (Laskin et al., 2002; Krueger et al., 2003), Fourier transform infrared spectroscopy in combination with EDX (Liu et al., 2008; Liu \& Laskin, 2009; Ryu \& Ro, 2009; Song et al., 2010; Song et al., 2013), laser-induced breakdown spectrometry (Beddows \& Telle, 2005), atomic absorption spectroscopy (Gorbunov et al., 2009), and proton-induced X-ray emission spectrometry compared to inductively coupled plasma atomic emission spectroscopy (Menzel et al., 2002). These techniques require expensive, bulky, equipment and highly trained sample preparation personnel. However, by comparison Raman spectroscopy offers a relatively economical solution to chemical identification and commercial solutions are now available in compact, portable, packages. The combination of aerodynamic diameter selectivity and Raman characterization therefore may offer a cost-effective and practical technique for the detection of potentially toxic aerosol particles and the speedy assessment of any associated exposure risks.

Raman spectroscopic data has been measured from aerosol particles in a variety of schemes before. Straightforward approaches include analysing material collected on a filter (Rosen \& Novakov, 1977; Mertes et al., 2004) or material impinged by a fluid which is then deposited and dried on a microscopy slide (Kong et al. 2011). More complex arrangements have also been used to directly analyze suspended particles (Schweiger, 1990) including; electrodynamic suspension (Buehler et al., 1991; Vehring et al., 1998; Lee \& Chan, 2007), optical trapping (Hoffmann et al., 1991; Hoffmann et al., 1995; Ling \& Li, 2013), or from a droplet chain arrangement (Vehring, 1998). In recent years Raman spectroscopy has also been utilised to identify particles collected by impaction (Sobanska et al., 2006; Batonneau et al., 2006; Ivleva et al., 2007; Ault et al., 2013, Avzianova \& Brooks, 2014). In addition, Raman spectroscopy has been combined with other techniques such as scanning electron microscopy 
(SEM) (Nelson et al., 2001), with SEM combined with X-ray analysis (Stefaniak et al., 2006; Worobiec et al., 2010; Sobanska et al., 2012), and more recently with atomic force microscopy, electron microscopy and X-ray analysis, and mass spectrometry (Sobanska et al., 2014).

The idea of using Raman spectroscopic information to create a chemically resolved spatial surface map has been around for some time (Delhaye \& Dhamelincourt, 1975). Raman spatial maps built up from pixels representing discrete sample points have seen some modest applications in recent years in the investigation of both non-biological (Batonneau et al., 2001; Sobanska et al., 2006; Batonneau et al., 2006) as well as biological (Tripathi et al., 2009; Schwarzmeier et al., 2013) aerosols. The same technique has also been used to study cell mitosis (Matthäus et al., 2006), to study the uptake and localization of various nanoparticles in hepatocarcinoma cells (Estrela-Lopis et al., 2011), to distinguish carbon nanotubes collected in a personal sampler (Keller et al., 2011) and to map solar radiation induced skin damage (Ali et al., 2013). In these studies Raman spectroscopy is used to identify particular chemical compounds, or to provide quantification of the relative contributions of different chemical compounds (Ivleva et al., 2007).

However none of these prior studies have allowed for the quantitative assessment of airborne particle exposure. Such an assessment approach is presented here based on quantitative analysis of sampled aerosol composition.

In this paper we extend the application of Raman spatial mapping. Image analysis is applied to the Raman spatial maps to quantify the number of particles and particle sizes present. By consideration of the sampling system and measurement time, these data can then be related back to what was originally present in the air. Glass slides are used as a sampling substrate, which give a complex Raman background spectrum to test the discrimination efficacy. In addition, in combination with a choice of larger agglomerates for analysis, the use of glass slides allows for validation of the approach by utilising optical microscopy as a reference method for discriminating the particles of interest. Immediately prior to collection of the Raman data, equivalent analysis is also applied to the optical microscopy images acquired from the same sample area. The results for the particle counts and sizes from the Raman maps are then compared to those obtained with optical microscopy. This provides a proof of concept study for the presented technique. However, in principle optical measurements are not required and hence their use does not represent a restriction on the applicability of this approach in general. 
Here $\mathrm{ZnO}$ particles (considered as agglomerated nanoparticles or nano-structured microparticles) are used as a test case material. $\mathrm{ZnO}$ is often used as an additive in sunscreens to block UV light. Whilst there is minimal risk from sunscreens due to the low penetration of $\mathrm{ZnO}$ through the skin, toxic responses to $\mathrm{ZnO}$ may pose a risk with inhaled material (Gulson et al., 2010; Smijs \& Pavel 2011; SCCS, 2012; Vandebriel \& De Jong, 2012).

\section{Methods}

The sampling setup is shown in Figure 1(a). The test aerosol is generated from $\mathrm{ZnO}$ powder (Sigma-Aldrich 205532) using a modified Naneum PA100 aerosolizer. In separate measurements with a Scanning Mobility Particle Sizer, the aerosolized powder is found to form an airborne state with a geometric mean particle size of $300 \mathrm{~nm}$ and geometric standard deviation of 1.63. However the underlying size distribution is not considered to be important for this proof of concept study. The setup is designed to provide a stabilized $\mathrm{ZnO}$ aerosol flow to two measurement instruments: (i) a 'TSI 3007 CPC', which is used to monitor the total concentration; and (ii) a 'Nano-ID ${ }^{\circledR}$ Select', which provides size segregated samples. The size bins available on the 'Nano-ID ${ }^{\circledR}$ Select' are detailed in Table 1. The impaction stages collect narrow bands of aerosol particles deposited along the centre of the chosen substrate (here standard glass microscopy slides), as shown in Figure 1(b). A number of sampling runs provided a range of deposited concentrations.

Table 1. Aerodynamic diameter ranges of the Nano-ID ${ }^{\circledR}$ Select sampling channels. The impaction stages show the lower D50 size cut-off with the upper size limit being set by the preceding stage or by the inlet geometry for the first stage. The diffusion stages are ordered in the reverse pattern in the flow path with the smaller particles being removed first.

\begin{tabular}{lcccccccccccc}
\hline Size Stage \# & $\mathbf{1}$ & $\mathbf{2}$ & $\mathbf{3}$ & $\mathbf{4}$ & $\mathbf{5}$ & $\mathbf{6}$ & $\mathbf{7}$ & $\mathbf{8}$ & $\mathbf{9}$ & $\mathbf{1 0}$ & $\mathbf{1 1}$ & $\mathbf{1 2}$ \\
\hline Min. cut-off diameter & 20 & 8.1 & 4.0 & 2.0 & 1.0 & 0.5 & 0.25 & 60 & 15 & 5 & 1.5 & 1 \\
\hline Max. cut-off diameter & $\sim 35$ & 20 & 8.1 & 4.0 & 2.0 & 1.0 & 0.5 & 250 & 60 & 15 & 5 & 1.5 \\
\hline & \multicolumn{8}{c}{ Impaction stages (size in $\mu \mathrm{m})$} & \multicolumn{1}{c}{ Diffusion stages (size in nm) } \\
\hline
\end{tabular}




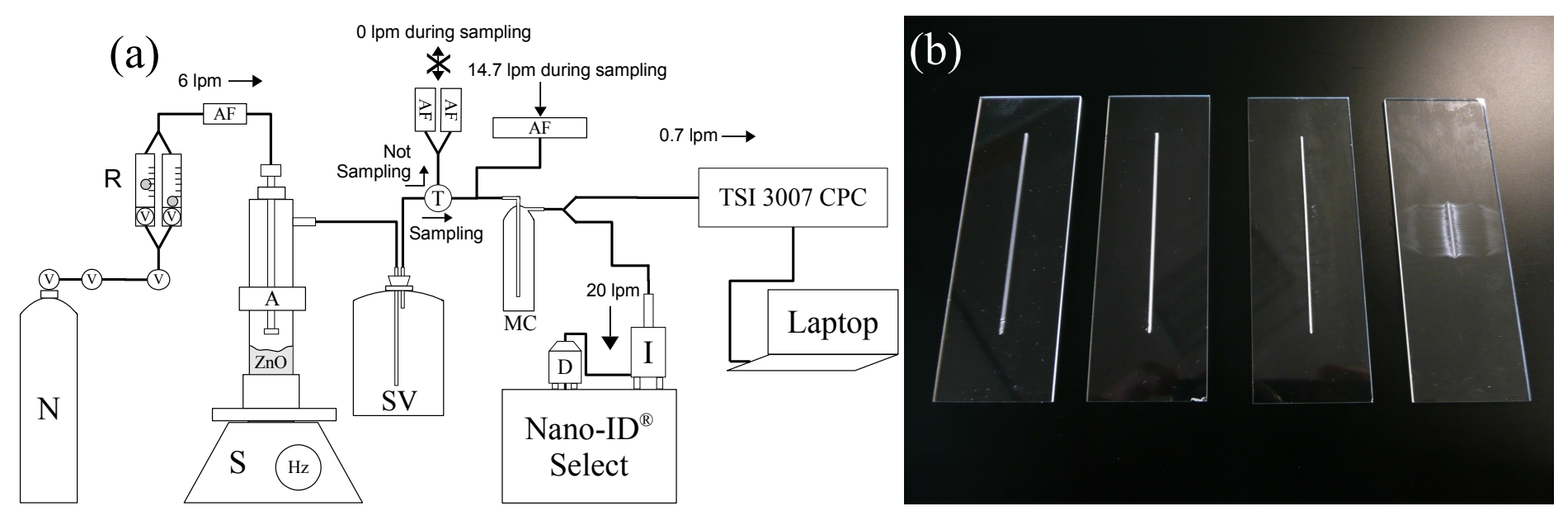

Figure 1. (a) - Sampling setup. N: Nitrogen tank; V: valve; R: rotameter; AF: air filter; A: aerosolizer; S: shaker, run at $15-20 \mathrm{~Hz}$; SV: Stabilisation Volume of 18.9 litres; T: three-way switching valve; MC: Mixing Chamber. I: impactor stages on Nano-ID ${ }^{\circledR}$ Select; D: diffusion net stages on Nano-ID ${ }^{\circledR}$ Select (not used apart from final filter stage). (b) - Example sample set from

run $\mathrm{H}$ showing impactor stages $4-7$ from left to right which correspond to aerodynamic equivalent diameter ranges $2-4 \mu \mathrm{m}, 1-2 \mu \mathrm{m}, 0.5-1 \mu \mathrm{m}$ and $0.25-0.5 \mu \mathrm{m}$ respectively.

Raman data was collected from a $31 \times 31$ point grid with a $2 \mu \mathrm{m}$ spacing between each point using a Horiba LabRam-HR with an external $473 \mathrm{~nm}$ excitation laser and $\times 50(\mathrm{NA}=$ 0.55) objective lens. Particular spectral features indicative of $\mathrm{ZnO}$ were chosen and their intensity mapped to either a greyscale or colour (with different component contributions) pixel value for each measurement point on the grid. Combining these pixels into a single image yields the resulting Raman map, showing the distribution of the chosen spectral features (and hence compound of interest) in the chosen grid area. Sample slides were positioned and focussed using an integrated computer controlled stage. Starting from a lengthwise central point on the edge of the slide, where the xyz stage coordinates were zeroed, the total width of the slide ('y-value') was measured using the xyz microscopy stage readout. This $y$-value was then divided by 2 and then input into the stage positioning software to give a centrally chosen point without any preview, avoiding any researcher bias. Sample areas were imaged using an optical microscope and an integrated white light source in transmission mode. Horiba's 'Lab-Spec 5' software was used for data acquisition and generation of contour maps to identify $\mathrm{ZnO}$ particles based on their 435, 1613 and $1724 \mathrm{~cm}^{-1}$ Raman peaks (see Figure 2) in the ZnO Raman spectrum (Alim et al., 2005). 
The image processing package 'Fiji' (distribution of 'ImageJ' - Abràmoff et al., 2007) was used to process the microscope images, to produce Raman contour maps and to carry out counting and sizing analyses. Counts were also performed by eye with the aid of a cell counter plug-in to mark particles and keep track of counts. The results of this manual count were compared to those obtained with the semi automated process. Software analysis involved processing and thresholding the images to allow a particle analysis algorithm to distinguish and demarcate particles from background. Firstly the scale is measured off the image and applied to the image such as to provide the software with a conversion from pixel values to distance in micrometres. The full field of view of the particles is then selected and a 4 pixel median filter is applied to smooth out noise and artefacts while retaining the edge sharpness of the particles. The contrast and brightness of the image is optimised before converting it to 8-bit greyscale. A threshold is then applied to create a binary distinction on the image between "particles" and "background". The resulting image is then selected again and Fiji's "Analyze Particles" routine can then be run with the necessary restrictive parameters on acceptable limits of particle size (e.g. 0.35 - infinity $\mu \mathrm{m}^{2}$ ) and circularity (defined as $4 \pi\left\{\right.$ area/perimeter $\left.{ }^{2}\right\}-$ e.g. $\left.0.1-1\right)$. The output can then be set to display the measured outlines of particles as well as measured counts, sizes and other parameters. For the purposes of this study it was decided to use the measured area and convert it to a single, circular equivalent size parameter " $d_{\text {equiv }}$ ". Counts and sizing were compared between the Raman and microscopy data. In the case of optical microscopy results, this routine will characterize any and all particles visible on the substrate. However, when the same routine is utilized on Raman maps, it can be used to measure only the particles of interest from the relevant Raman peak(s). In this proof of concept study we examine $\mathrm{ZnO}$ particles on a glass substrate that gives a significant Raman background on which the $\mathrm{ZnO}$ signal has to be positively identified. This allows us to assess the effectiveness of the Raman data in measuring the size and number of particles present by direct comparison to the optical microscopy results. The validation approach employed for this study requires the case where the compound of interest is optically distinct from the background such that the data can be correctly correlated between the Raman and optical microscopy data. This leads to the requirement for the use of larger particles here. However the optical microscopy data is not in general required and therefore it is not a limitation on the applicability of the overall approach. 

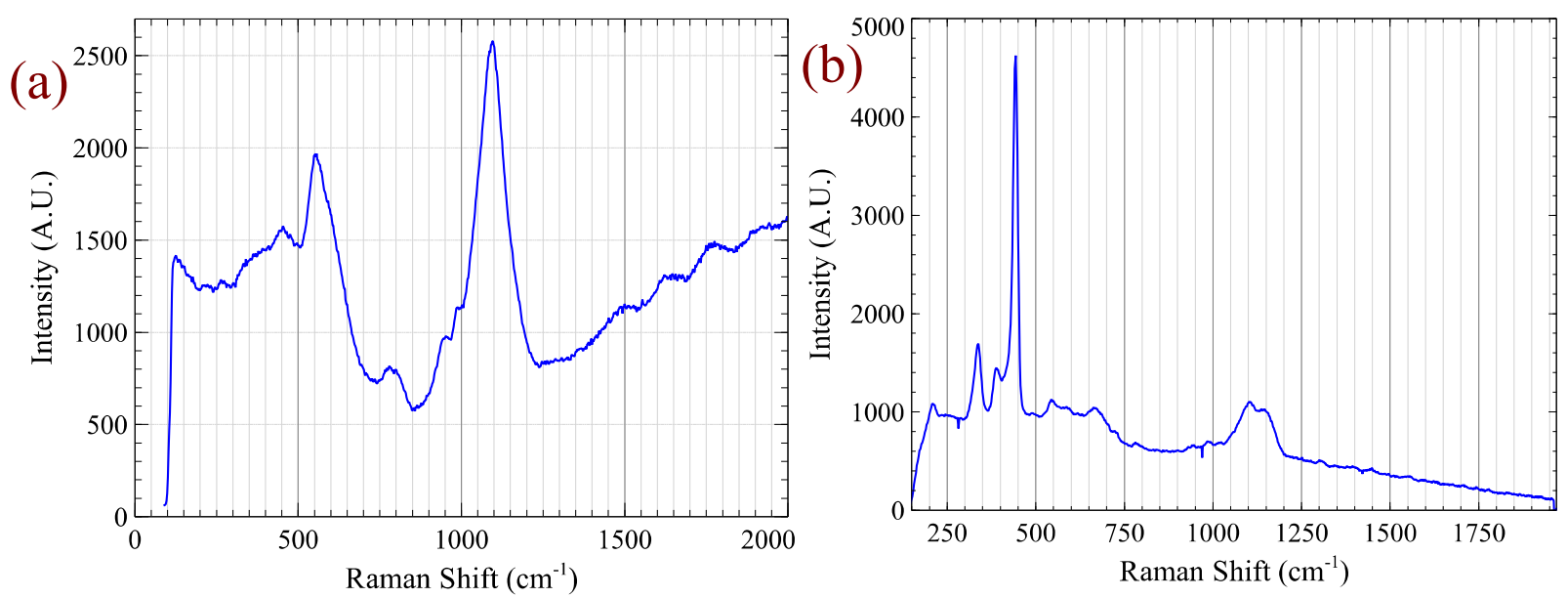

(c)

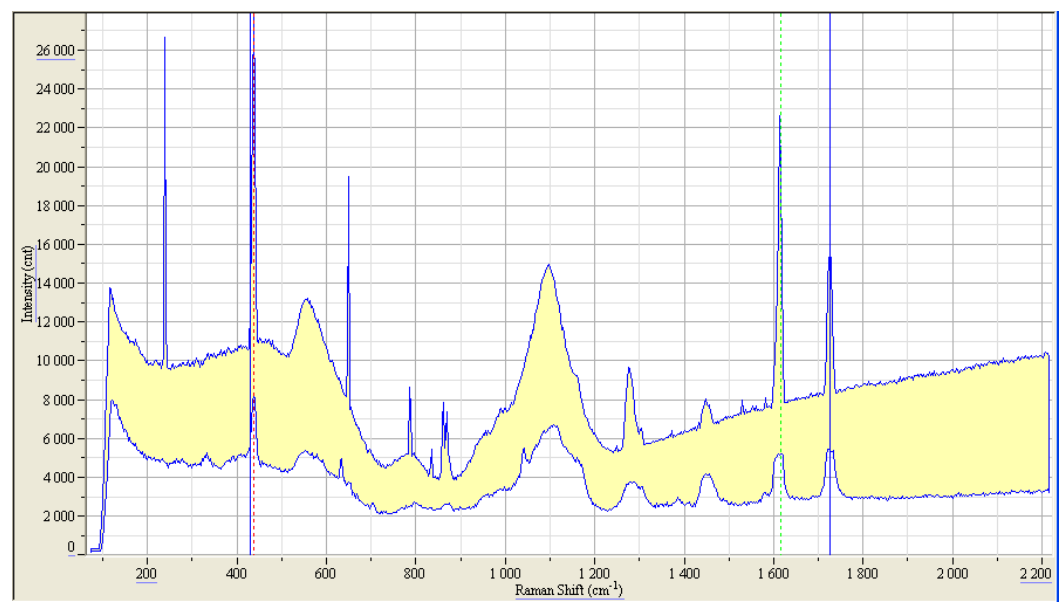

Figure 2. (a) - Example background Raman spectrum measured from a clean glass slide. The $\mathrm{SiO}_{2}$ line is dominant at $1100 \mathrm{~cm}^{-1}$ and is still clearly apparent when measuring $\mathrm{ZnO}$ particles on the slide as seen in (c). (b) - ZnO Raman spectrum measured directly from a bulk powder sample from a powder well. (c) - Example range of ZnO Raman spectra obtained from the measurement grid used on the glass slide sample C4 (ref. Figure 3). The plot shows the limits from all of the 961 individual spectra from each grid position. The Stokes peaks used to distinguish $\mathrm{ZnO}$ particles from background in the resulting data maps are marked at 435, 1613 and $1724 \mathrm{~cm}^{-1}$ respectively. Note that these latter two peaks are found to be associated with the $\mathrm{ZnO}$ particles only in these impaction samples, and did not appear in the spectra from powder well samples. Therefore they may be related to some surface contaminant on the $\mathrm{ZnO}$ particles picked up during the sample aerosolisation, impaction or subsequent handling of the sample.

\section{Results}

The experiment was conducted in four stages. First, aerosols were generated from $\mathrm{ZnO}$ powder; see Figure 1(a). Second, airborne particles of $\mathrm{ZnO}$ were collected onto glass slides. After that Raman spectra of slides containing $\mathrm{ZnO}$ particles were recorded. And finally, data were analysed. 
Sampling periods were adjusted to achieve different concentrations. Table 2 shows the measured total number of particles which passed through the Nano-ID ${ }^{\circledR}$ Select during each sampling interval, calculated from the number concentration measured by the $\mathrm{CPC}$ (representing all the particle sizes), sampling time and the sampling flow rate. Sampling intervals ranged from 15 seconds to 10 minutes with the target of collecting a range of concentrations within the constraints of having sufficient numbers for representative statistics whilst avoiding overlap of neighbouring particles. Clearly separated particles are necessary to provide a correct count, and therefore, if higher concentrations or longer sampling times are needed, either a diluter or multiple shorter samples may be required. Samples were collected from size stages $4-7$, covering a total size range of $0.25-4 \mu \mathrm{m}$ (Table 1 ). The relative differences between the total sampling concentrations are the same as the relative differences across any particular size channel only if the shape of the size distribution remains the same throughout.

Table 2. Total sampling throughput for each of the eight sampling runs.

\begin{tabular}{lcccc}
\hline \multicolumn{1}{c}{ Sample } & A & B & C & D \\
\hline $\begin{array}{l}\text { Total throughput: } \\
\text { (No. of Particles) }\end{array}$ & $9.19 \times 10^{6}$ & $2.46 \times 10^{7}$ & $4.05 \times 10^{7}$ & $1.06 \times 10^{8}$ \\
\hline \multicolumn{1}{c}{ Sample } & E & F & G & H \\
\hline $\begin{array}{l}\text { Total throughput } \\
\text { (No. of Particles) }\end{array}$ & $2.34 \times 10^{8}$ & $3.33 \times 10^{8}$ & $8.28 \times 10^{8}$ & $1.54 \times 10^{9}$ \\
\hline
\end{tabular}

Each individual sample is designated with the letter from Table 2, indicating the sample run concentration with the channel number from Table 1, indicating the channel size range. Stage 4 samples in the concentration range B - F were chosen for this Raman study (the specific samples from stage 4 for each concentration shall henceforth be designated B4 - F4). The larger particle size allows for the requisite comparison to microscopy results, while the concentration range chosen gave reasonable count statistics and particle overlap without needing to adjust the analysis process. An overview of the optical and sub-area Raman results achieved for the selected samples B4 - F4 are presented in Figure 3. This shows the microscopy images of the chosen sample areas (left column), positioning of the Raman grid relative to each sample (middle column) and resultant smoothed Raman data generated from signal intensity in $\mathrm{ZnO}$ Raman peaks (right column) for five different sample concentrations deposited on stage number 4 of the Nano-ID ${ }^{\circledR}$ Select. The sampled areas were systematically chosen from the central region of the particle deposit as described in the previous section. 


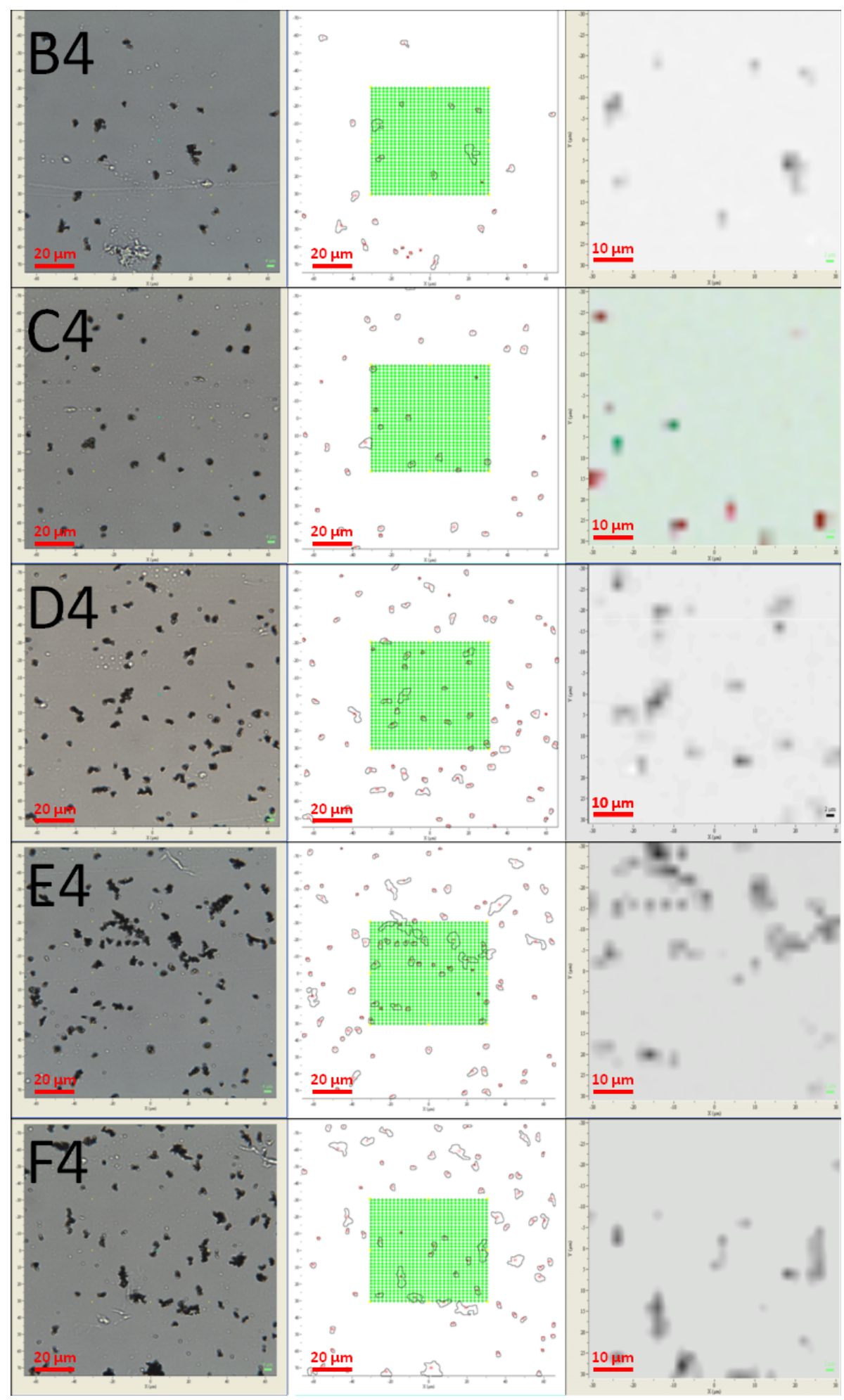

Figure 3. Overview of images acquired for samples B4 - F4. The full microscopy field of view is shown on the left column. The $31 \times 31$ grid arrangement for Raman measurements is shown in the centre column and is overlaid on top of a post-processed version of the microscopy images showing the measured outlines of particles. The right column shows the resulting smoothed Raman data as output from Lab Spec 5 utilising the 435, 1613, and $1724 \mathrm{~cm}^{-1} \mathrm{ZnO}$ peaks. 
As well as providing a reference for the Raman data, the optical microscopy images are also useful for testing the efficacy of the automated particle sizing and counting procedure. The accuracy of automated counting is compared to that obtained manually by eye (with assistance of the "Cell Counter" Fiji plugin) for the microscopy and Raman data in Figure 4. The counts obtained from the automated counting of Raman and microscopy data from the same samples (B4 - F4) are compared in Figure 5. The auto analysis routine provides a measured projected area $(A)$ of the particle in units of $\mu \mathrm{m}^{2}$, once the appropriate scale has been set in the software. This has been converted to a circular equivalent diameter $d_{\text {equiv }}(\mu \mathrm{m})$ such that $d_{\text {equiv }}=2 \sqrt{A / \pi}$. Number density distributions for $d_{\text {equiv }}$ are shown in Figure 6 , and Figure 7 provides a direct comparison of sizing between the microscopy and Raman data.
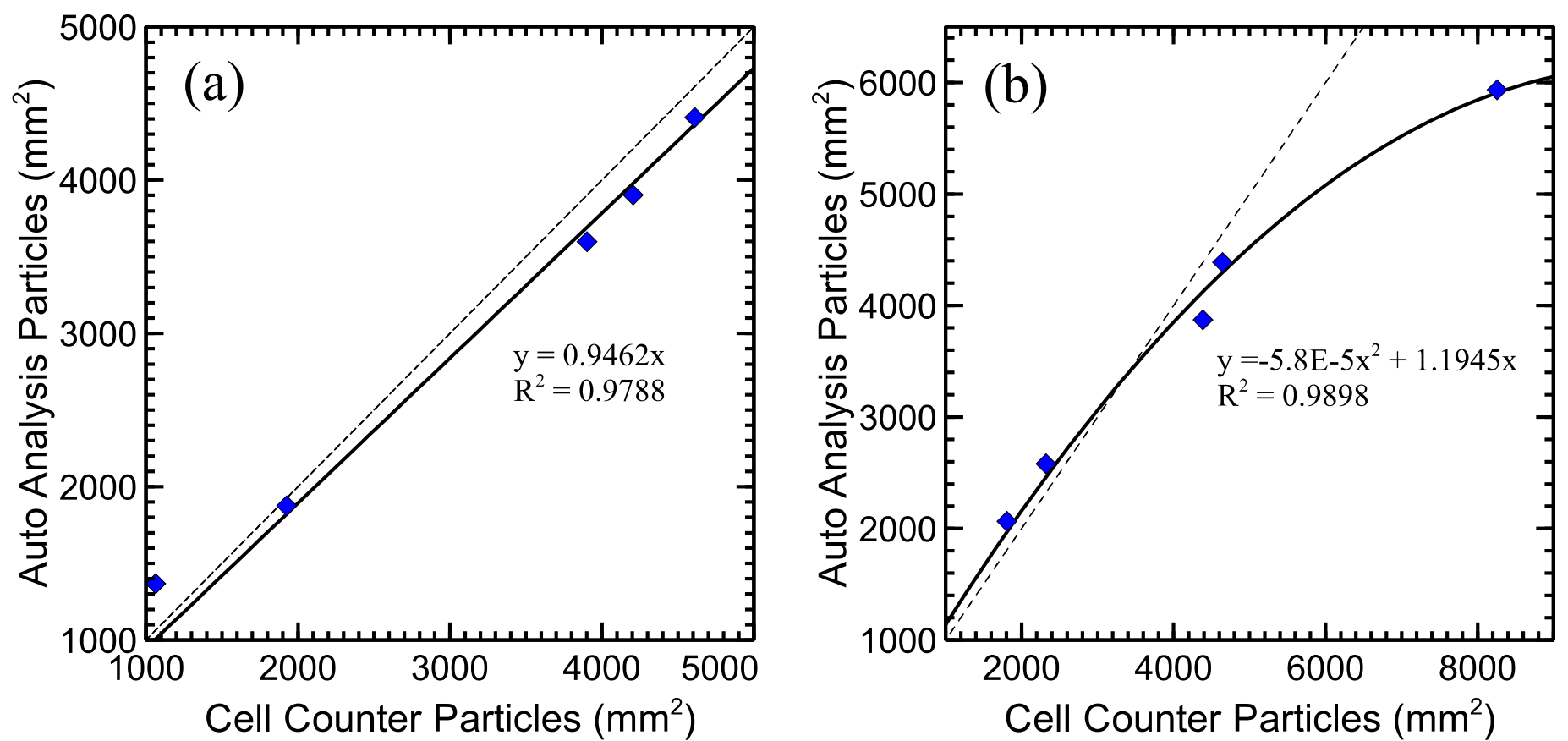

Figure 4. Comparison of counts per unit area achieved with automatic image analysis / thresholding (Auto Analysis) compared to counting by eye and marking particles (Cell Counter) for the microscopy (a) and Raman (b) images from samples B4 - F4. Dashed lines show a perfect $\mathrm{y}=\mathrm{x}$ correlation while solid lines show fits to the data with associated fitting parameters. 


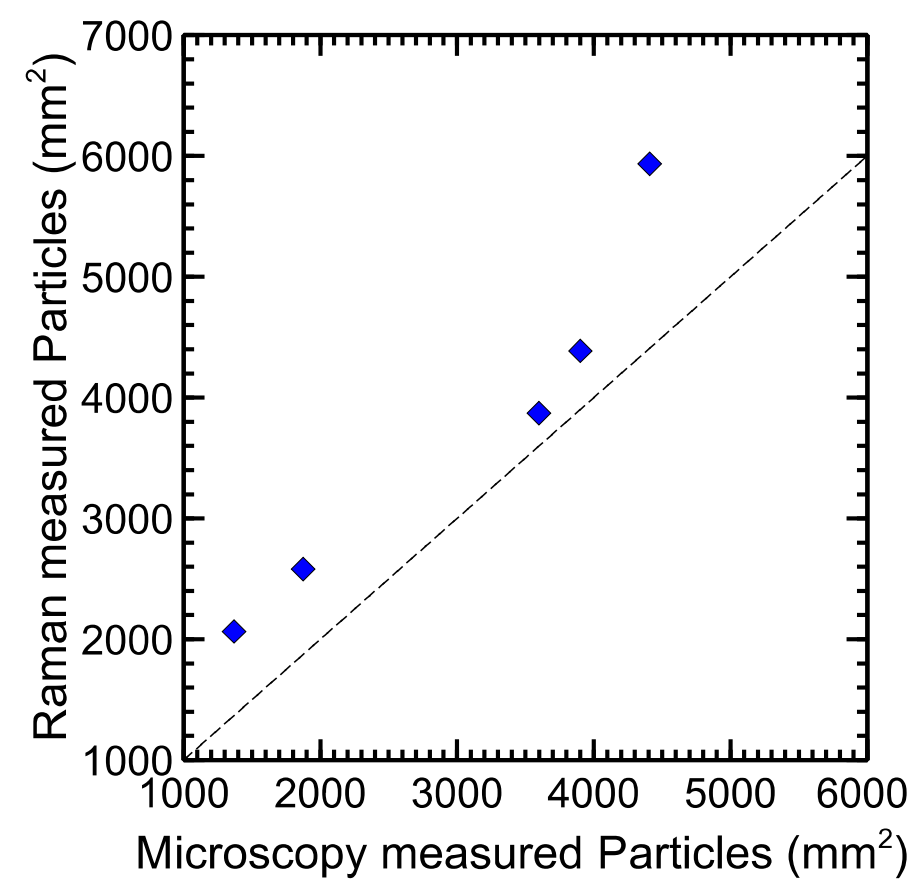

Figure 5. Comparison of particle concentration measured from the Raman data to that measured from the optical microscopy data. A perfect correlation is shown by the dashed $(y=x)$ line.
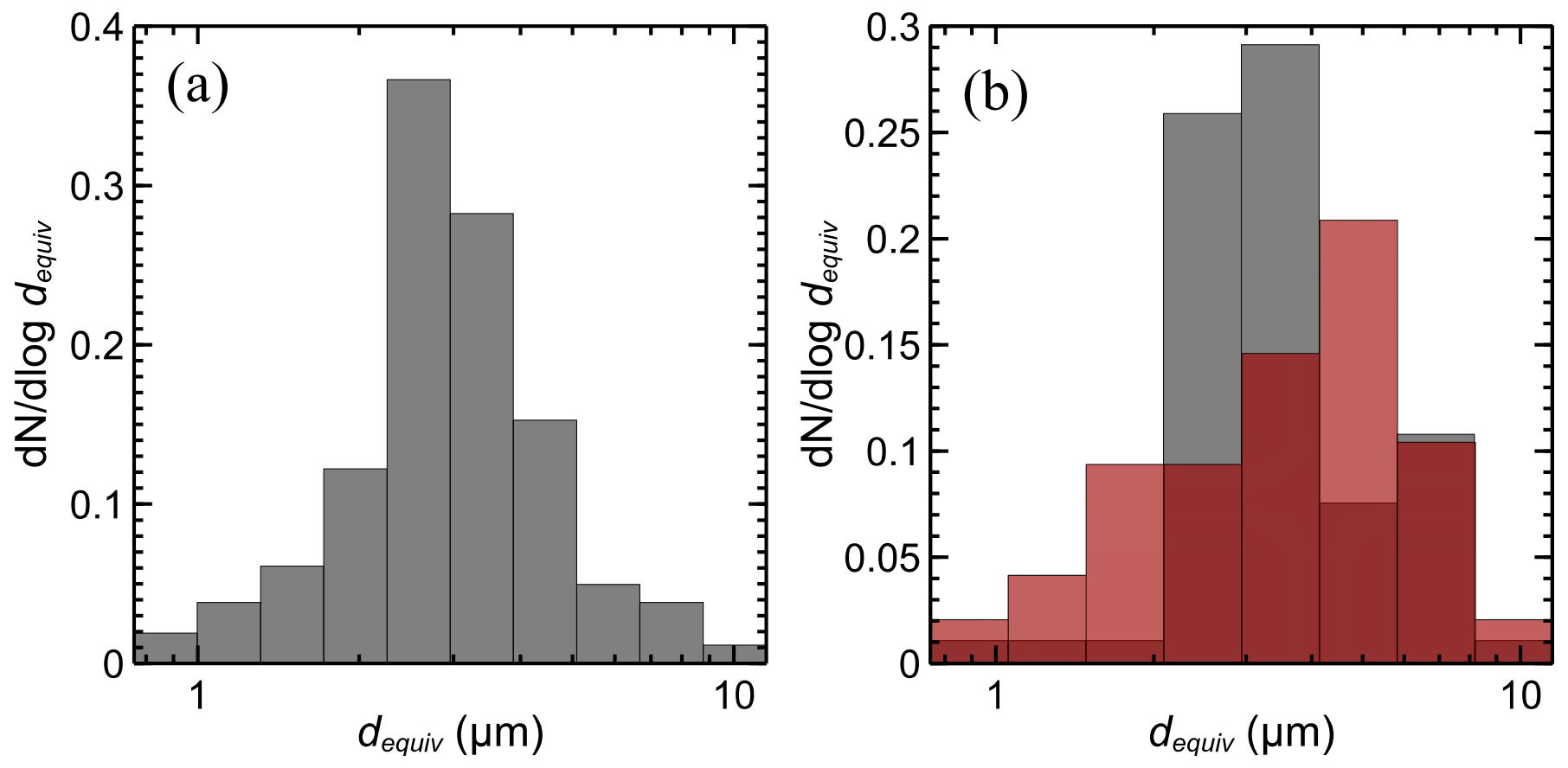

Figure 6. (a) - Size distribution of all particles measured from size stage number 4 microscopy images.

(b) - Comparison of size distribution from Raman measurements (red, overlaid semi-transparent) compared to the same set of particles measured with microscopy (grey). The y-axis shows the number $(N)$ density per log unit size. 


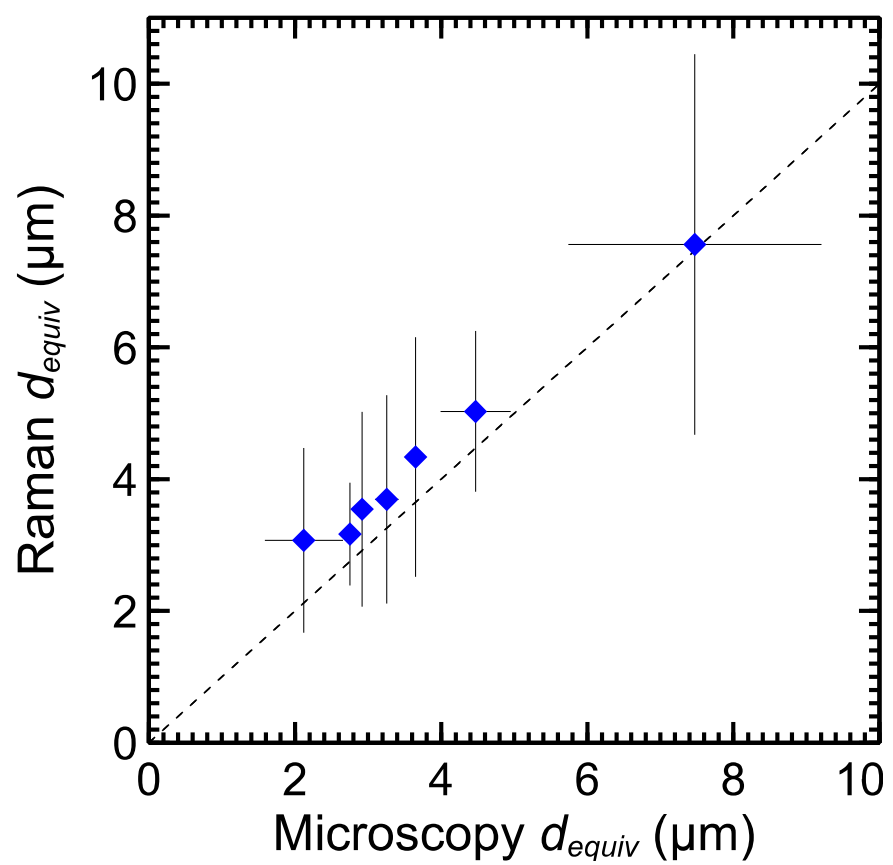

Figure 7. Particle size measurement comparison between the Raman and microscopy images. Each marker represents a 15 point data cluster with error bars showing the standard deviation of each cluster.

\section{Discussion}

Obtaining correct information from Raman maps requires some careful consideration. Many parameters need to be optimized and verified to characterize ENP correctly. These include; the spot size and intensity of the Raman laser source, transversal resolution from the grid density, sampling time, and statistical characterizations of the particle ensemble. With the correct choice of Raman spectroscopy parameters it can be seen (Figure 3) that $\mathrm{ZnO}$ particles can be reliably resolved, even when using a sampling resolution (here 2 microns) comparable to the particle size. Figure 4(a) demonstrates that particles distinguishable by eye in the image can be accurately counted with automatic image analysis. Accurate counting and sizing is also demonstrated in Figure 3 by comparison of the measured particle outlines in the middle column to the raw optical images in the left column. This technique has been successfully carried over for processing the Raman data.

The critical step in the image processing procedure is the thresholding step, where each pixel is limited to a binary distinction between "particle" and "background". Setting the threshold level too high will result in the merging of neighbouring particles, whilst setting the level too low results in smaller particles or those with a lower contrast to the background not 
being measured. Due to the constant light levels in the microscopy images, it was possible to use the same level adjustment across all of the optical images. Therefore, in theory the analysis could have been fully automated for the microscopy images. However for the Raman map images, there was some adjustment of contrast/brightness and thresholding steps from image to image, and so additional work would be required here to fully automate this process. Further study may allow the entire process to be made fully autonomous with tighter controls on the Raman mapping parameters, or by developing an effective thresholding algorithm.

The correlation to manual counts in Figure 4(b) tails off at higher concentrations, which can be attributed to the comparatively low transversal resolution of the Raman data obtained using a $2 \mu \mathrm{m}$ grid spacing. This results in an increased overlap of adjacent particles at higher concentrations, causing the analysis routine to measure multiple particles as one. This leads to under-counting and over-sizing. The over-sizing can be seen in the shift in the Raman distribution in Figure 6(b), as well as the greater abundance of data points above the 1:1 dashed line shown in Figure 7. The grid resolution was deliberately kept low in this study to allow for a large enough area to be measured to generate useful statistics within reasonable measurement times ( 70 minutes for each of the 961 point Raman maps acquired in this study). For a given sampling period, higher concentrations of particles in the air would lead to a higher deposited concentration, and hence increased particle overlap. However, this situation can be avoided for higher concentration aerosols, by either reducing the sampling time and volume of air sampled, diluting the aerosol by a known ratio prior to sampling, or by taking multiple shorter samples over the course of the desired total sampling period. The sampling approach should be optimised for any given exposure scenario. For example, longer sampling periods may be required to provide a representative exposure assessment over a working shift, while the relevance of the chosen sampling point to personal exposure should also be taken into account.

A higher grid resolution (down to $500 \mathrm{~nm}$ ) could also be used to more clearly distinguish particles. The limits on resolution will ultimately be set by the spot size of the laser. Spot sizes with a full-width at half-maximum of $<1 \mu \mathrm{m}$ have been achieved utilizing a $\times 100(\mathrm{NA}=0.8)$ objective lens. However, super resolution approaches have recently led to the development of Raman mapping techniques for aerosol particles with a spatial resolution as low as $200 \mathrm{~nm}$ (Offroy et al., 2015). Here we focussed on particles in the micron size range as a first proof of principle allowing for the required comparison to optical microscopy results. In addition, the 
$473 \mathrm{~nm}$ laser used in this study should offer improved transversal resolution (as well as improved Raman signal intensity) compared to the more commonly employed $633 \mathrm{~nm}$ laser.

As the $\mathrm{ZnO}$ particles were well resolved they could be counted reliably in the Raman data. Any offset from the microscopy data in counts as seen in Figure 5 can be attributed to the reduced statistical significance of the Raman data due to the reduced sample areas measured compared to the optical images.

The size distributions given in Figure 6 demonstrate that the $d_{\text {equiv }}$ size parameter chosen correlates reasonably well to the aerodynamic particle size (expected to be $2-4 \mu \mathrm{m}$ in this sampling stage). This may be expected for samples without complicated structural or fractal properties. The reduced resolution used for the Raman sampling can be seen to cause broadening of the size distribution and a slight shift to larger sizes due to neighbouring particles becoming merged. The limited transversal resolution, and difficulty in choosing a correct threshold in the software analysis, causes significant uncertainty in the particle sizes measured from the Raman data as seen in Figure 7. The critical point to bear in mind is that the aerodynamic particle size obtained from the sampling method is the size parameter of importance when considering particle deposition in the lung and associated health risks. However, it is interesting to note the potential for sizing information to be obtained from the Raman data alone. This could allow some approximate size information to be assigned to polydisperse particles obtained from a simpler sampling system, or provide more detailed characterization information when combined with the aerodynamic particle size obtained from the Nano-ID ${ }^{\circledR}$ Select.

The glass substrate used in this study (without $\mathrm{ZnO}$ particles) gives a complicated Raman spectrum: comprising amorphous $\mathrm{SiO}_{2}$, other unidentified lines (Figure 2(a)), a fluorescent background Raman signal and additionally, some contaminating particles (seen in the microscopy images in Figure 3). This generates a background signal that must be filtered out to identify the $(\mathrm{ZnO})$ particles of interest. Therefore, the clear, unambiguous detection of $\mathrm{ZnO}$ particles observed here, demonstrates the ability to resolve a specific chemical species against a contaminating background Raman signal. It is worth considering that the influence of interfering substances is likely to be scenario specific and under certain conditions such as mixed species agglomerates, the discrimination power of Raman will potentially be reduced. In addition, the Raman spectrum could be complicated by additional lines if multiple species inhabit the region covered by the laser spot size. However, these are standard challenges in 
the field, and, as long as a signal can be detected for a given species, the number of such signatures can be quantified and correlated to the aerodynamic size as defined by the sampling method.

This study has focussed on the micron size range to allow for proof-of-concept by comparison to microscopy images. The size range can be extended to sub-micron by changing the objective lens in the setup to a $\times 100$. Although reliable sizing information may not be achievable into the nanometre range from the Raman data alone, detection and some quantification should still be achievable. Particles which are smaller than the laser beam diameter still contribute to the Raman signal, but their size will be unresolvable by Raman alone. Here the segregated sampling could be of advantage to provide size-resolved information. The sensitivity of the approach can be further improved by considering more advanced Raman techniques such as Surface Enhanced Raman Spectroscopy (SERS), as achieved recently for aerosol particles (Craig et al., 2015), or Coherent Anti-Stokes Raman Spectroscopy (CARS), although the latter requires prior knowledge of the target material.

Although the Raman spectrometer system used in this study is certainly not compact, the approach should be equally possible utilising a small bench-top spectrometer coupled with an automated miniature translation stage.

Due to the large number of parameters in this study, it is difficult to assess the lower detection limit of this approach. However we can assess the potential sensitivity by considering the detection of a single particle in one grid area measurement. A high detection rate is considered to be justified by the good correlation between the optical microscopy and Raman results shown in Figure 3. The Raman map grid area used (as shown in the centre column of Figure 3) is $3,600 \mu \mathrm{m}^{2}$ and a total deposit area on the slide is $50 \mathrm{~mm}^{2}$. If we assume uniform deposition across the deposit area, a single detected particle in a grid would correspond to a total of $\sim 14,000$ particles deposited on the slide. If we conservatively estimate that only particles in the diameter range $\left(d_{\text {equiv }}\right)$ of $2-4 \mu \mathrm{m}$ will be reliably detected by our 2 $\mu \mathrm{m}$ grid spacing, this leads to a deposited mass sensitivity of $\sim 200 \mathrm{ng}$ (assuming spherical particles of density $1,000 \mathrm{~kg} / \mathrm{m}^{3}$ ). While considering the detection of one of the smallest particles seen above $(\sim 0.7-0.8 \mu \mathrm{m})$ gives a total deposited mass of $\sim 3 \mathrm{ng}$. These values are approximate estimates, especially in the latter case where the measured size from the image is smaller than can be properly resolved, and there starts to be significant probability of being missed by the sampling grid due to undersampling. However, the values obtained can be taken 
as indicative of the order of mass sensitivity available, even without optimization of the system. Clearly this could be improved on simply by measuring a larger area of the deposit, or by adjusting the Raman setup for better sensitivity to smaller particles, or by increasing the density of the deposit with better particle focussing in the sampling system.

These estimates can be used to evaluate the number concentration and the mass concentration of airborne particles. For $2-4 \mu \mathrm{m}$ particles the lowest number concentration is $14,000 / \mathrm{V}$, where $\mathrm{V}$ is the sampling volume. The Nano-ID ${ }^{\circledR}$ Select sampling flow rate is 20 litres/min. If we consider a typical sampling time of 100 minutes, the sampled volume $\mathrm{V}$ is therefore 2,000 litres or $2 \mathrm{~m}^{3}$. The lower detection limit of the number concentration of particles is then 7,000 per $\mathrm{m}^{3}$ or $7 \times 10^{-3}$ particles per $\mathrm{cm}^{3}$.

From the above, the lower mass concentration limit of $2-4 \mu \mathrm{m}$ particles is $200 \mathrm{ng} / 2 \mathrm{~m}^{3}$ equal to $100 \mathrm{ng} / \mathrm{m}^{3}$. This is considerably lower than the majority of exposure limits for toxic substances. Thus, Raman chemical speciation, quantified in the manner described above, may have practical application in evaluating potential health risks at working places. However, it must also be recognised that the presented method is only applicable to Raman active materials, and only for materials with distinct signatures. The potential impact on the sensitivity due to increased relative loading of other species can also not be ignored. The requirement for a transparent background for optical validation precluded investigation of these effects in the present study, however it is clear that quenching of the sensitivity can only occur in the situation where the interfering species is found within the same laser spot area as the target of interest. Therefore, overloading of the slides should be avoided to mitigate against any possibility of this occurring.

Importantly it is known that nanoparticles will generally agglomerate resulting in submicron or micrometer sized clusters. The aerosols obtained in this paper were generated from typical commercial samples currently in use in the nanotechnology industry.

\section{Conclusions}

A new approach has been developed and demonstrated for the quantification of exposure to airborne particles and nanomaterials. Size resolved sampling is combined with Raman spectroscopic spatial mapping analysis to provide chemically distinguished quantification of $\mathrm{ZnO}$ particles. This combination considerably reduces or eliminates uncertainties related to 
the sensitivity of the Raman signal to particle size. Therefore, in this way a quantitative evaluation of $\mathrm{ZnO}$ particle number and mass with Raman spectroscopy becomes possible. The test case particles are shown to be reliably detected in the Raman data, and can be counted and sized in a manner which is at least comparable to what is achievable with optical microscopy imaging. The most significant advantage of using a Raman mapping approach is the crucial chemical information acquired, allowing different species to be discriminated, enabling a determination of the concentration of benign and toxic particles in a sample. Although this comes with a time penalty compared to optical imaging, it adds significantly to the value of the data.

There is still some debate as to what the most significant metric is for determining the toxicity of airborne pollutants (e.g. number, mass, surface area, etc.), but it is generally recommended to gather as much chemically selective and other distinguishing information as possible. The aerodynamically selected first stage used here is critical in determining aerosol deposition in the respiratory tract. Combined with Raman quantification, a specific measure of exposure can be obtained. Ongoing progress in the development of miniature Raman systems, and miniature translation stages as required for mapping, opens the possibility of using this technique as a tool for in situ occupational hygiene health risk assessment.

The lower detection limit of the described approach is conservatively estimated at $200 \mathrm{ng}$ in a sample. Given a sampling time of 100 minutes this would correspond to a number concentration sensitivity of $7 \times 10^{-3} \mathrm{~cm}^{-3}$ or a mass concentration sensitivity of $100 \mathrm{ng} / \mathrm{m}^{3}$. The sensitivity of this technique is therefore more than sufficient to cover the majority of occupational hygiene exposure risk requirements.

This technique is considered to have potential application across a broad range of aerosol particle sizes albeit only for species with a distinct Raman signature. In practice the upper size limit will be determined by the sampling approach. The smallest detectable size will be sample dependent and limited by the minimum detectable Raman signal required for positive identification. However, as the particle size reduces much below the laser spot sizes, the risk of under counting due to multiple particles being measured as one within the same laser spot area is increased. Reduced sample loadings can help to avoid this issue. Sensitivity will likely be improved by removing the need for a glass substrate as required only in this proof of concept study. A substrate with a lower background Raman signal would interfere less with the data signals. 
Considering how well this technique might fare when applied to a multicomponent aerosol as encountered in workplace or environmental studies - as long as sample loading is restricted to avoid any more than one particle at a time being measured, then there should not be any reduction in sensitivity compared to measuring any particular component in isolation as carried out here. However, additional analysis time would be required to separately identify, suitably threshold and then count each component. Automated identification through the use of Raman spectral libraries could provide significant time and labour savings in this area. Also, larger sample areas, leading to longer Raman measurement times, may be required to provide acceptable count statistics for each component depending on the fraction of the total matrix they represent, and in consideration of the fact that the sample loading limits will be determined by the total concentration of all components combined. Although one might consider that multiple particle types with distinguishable Raman spectra falling within the same laser spot area could still be counted separately, in practice they could not be distinguished from a single particle of heterogeneous composition without additional a priori information on the nature of the aerosol. In any case multiple particles falling within the same spot area should be avoided as mentioned above due to the risk of under counting multiple particles of the same composition. Although it would be possible to automate much of the data analysis carried out here, the time required to measure each sample map (over an hour in this study), on top of the concentration dependent sampling time, is still a fundamental limitation on the speed of this approach.

The main advance in measurement brought about by this study is a method to provide quantitative measurements of aerosol concentrations of different chemical species separated into exposure relevant size fractions by the combined use of aerodynamic size-resolved sampling with Raman spatial mapping.

\section{Acknowledgements}

Brian Steer extends his gratitude to the University of Kent and Naneum Ltd. for their support of his $\mathrm{PhD}$ studentship.

This work was conducted as part of PROSPEcT, which is a public-private partnership between DEFRA, EPSRC and TSB and the Nanotechnology Industries Association (NIA Ltd.) and its members, and was administered by the DEFRA LINK Programme. 


\section{References}

Abràmoff, M. D., Magalhães, P.J. and Ram, S.J. (2004). Image Processing with ImageJ. Biophot. Int. 11 (7): 36-42.

Ali, S.M., Bonnier, F., Ptasinski, K., Lambkin, H., Flynn, K., Lyng, F.M. and Byrne, H.J. (2013). Raman Spectroscopic Mapping for the Analysis of Solar Radiation Induced Skin Damage. Analyst (March 8).

Alim, K.A., Fonoberov, V.A., Shamsa, M. and Balandin. A.A. (2005). Micro-Raman Investigation of Optical Phonons in ZnO Nanocrystals. J. Appl. Phys. 97 (12): 124313.

Ault, A.P., Zhao, D., Ebben, C.J., Tauber, M.J., Geiger, F.M., Prather, K.A. and Grassian, V.H. (2013). Raman Microspectroscopy and Vibrational Sum Frequency Generation Spectroscopy as Probes of the Bulk and Surface Compositions of Size-resolved Sea Spray Aerosol Particles. Phys. Chem. Chem. Phys.: PCCP 15 (17) (May 7): 6206-14.

Avzianova, E., and Brooks, S.D. (2014). Analysis of Nickel (II) in Particulate Matter by Raman Microspectroscopy. J. Aerosol Sci. 67 (January): 207-214.

Batonneau, Y., Laureyns, J., Merlin, J.-C. and Brémard, C. (2001). Self-modeling Mixture Analysis of Raman Microspectrometric Investigations of Dust Emitted by Lead and Zinc Smelters. Anal. Chim. Acta 446 (1-2) (November): 23-37.

Batonneau, Y., Sobanska, S., Laureyns, J. and Brémard, C. (2006). Confocal Microprobe Raman Imaging of Urban Tropospheric Aerosol Particles. Environ. Sci. Technol. 40 (4) (February 15): 1300-6.

Beddows, D.C.S. and Telle, H.H. (2005). Prospects of Real-time Single-particle Biological Aerosol Analysis: A Comparison Between Laser-induced Breakdown Spectroscopy and Aerosol Time-of-flight Mass Spectrometry. Spectrochim. Acta B. 60 (7-8) (August): 10401059.

Buehler, M.F., Allen, T.M. and Davis. E.J. (1991). Microparticle Raman Spectroscopy of Multicomponent Aerosols. J. Colloid Inter. Sci. 146 (1): 79-89. 
Chow, J. C. (1995). Measurement Methods to Determine Compliance with Ambient Air Quality Standards for Suspended Particles. Journal of the Air \& Waste Management Association, 45(5), 320-382.

Chow, J. C., Doraiswamy, P., Watson, J. G., Chen, L.-W. A., Ho, S. S. H., \& Sodeman, D. A. (2008). Advances in integrated and continuous measurements for particle mass and chemical composition. Journal of the Air \& Waste Management Association, 58(2), 141163.

Craig, R. L., Bondy, A. L., \& Ault, A. P. (2015). Surface Enhanced Raman Spectroscopy Enables Observations of Previously Undetectable Secondary Organic Aerosol Components at the Individual Particle Level. Analytical Chemistry, 87 (15), 7510-7514.

Delhaye, M., and Dhamelincourt. P. (1975). Raman Microprobe and Microscope with Laser Excitation. J. Raman Spectros. 3: 33-43.

Donaldson, K., Stone, V., Gilmour, P.S., Brown, D.M. and MacNee, W. (2000). Ultrafine Particles: Mechanisms of Lung Injury. Philos. T. R. Soc. A. 358 (1775): 2741-2749.

Eggersdorfer, M. L., and Pratsinis, S. E. (2014). Agglomerates and aggregates of nanoparticles made in the gas phase. Advanced Powder Technology, 25(1), 71-90.

Estrela-Lopis, I., Romero, G., Rojas, E., Moya, S.E. and Donath, E. (2011). Nanoparticle Uptake and Their Co-localization with Cell Compartments - a Confocal Raman Microscopy Study at Single Cell Level. J. Phys. Conf. Ser. 304 (July 6): 012017.

Gorbunov, B, Priest, N.D., Muir, R.B., Jackson, P.R. and Gnewuch, H. (2009) A Novel Sizeselective Airborne Particle Size Fractionating Instrument for Health Risk Evaluation. Ann. Occup. Hyg. 53 (3): 225-37.

Gouadec, G., and Colomban, P. (2007). Raman Spectroscopy of Nanomaterials: How Spectra Relate to Disorder, Particle Size and Mechanical Properties. Prog. Cryst. Growth Ch. 53 (1) (March): 1-56.

Gulson, B., McCall, M.J., Korsch, M., Gomez, L., Casey, P., Oytam, Y., Taylor, A., McCulloch, M., Trotter, J., Kinsley, L. and Greenoak, G. (2010). Small Amounts of Zinc from Zinc Oxide Particles in Sunscreens Applied Outdoors Are Absorbed Through Human Skin. Toxicol. Sci. 118 (1) (November): 140-9. 
Hoffmann, G.G., Oelichmann, B. and Schrader, B. (1991). Raman Spectroscopy of Optically Trapped Single Aerosol Particles. J. Aerosol Sci. 22 (S.1): S427-S430.

Hoffmann, G.G., Lübben, J.F. and Schrader, B. (1995). Composition Analysis of Optically Levitated Aerosol Single Particles. J. Mol. Struct. 349 (95) (April): 145-147.

Horn, I., and Günther, D. (2003). The Influence of Ablation Carrier Gasses Ar, He and Ne on the Particle Size Distribution and Transport Efficiencies of Laser Ablation-induced Aerosols: Implications for LA-ICP-MS. Appl. Surf. Sci. 207: 144-157.

Huong, P.V. and Verma, A.L. (1990). Characterization of Materials by micro-Raman Spectroscopy. Mater. Sci. Eng. B. 5 (2): 255-260.

Ivleva, N. P., McKeon, U., Niessner, R. and Pöschl, U. (2007). Raman Microspectroscopic Analysis of Size-Resolved Atmospheric Aerosol Particle Samples Collected with an ELPI: Soot, Humic-Like Substances, and Inorganic Compounds. Aerosol Sci. Tech. 41 (7) (June 5): $655-671$.

Keller, M., Kreck, G., Holzapfel Y., Neubauer N., and Seipenbusch M. (2011). Monitoring Method for Carbon Nanotubes (CNT): Personal Sampler and Corresponding Reading Device. Proc. Int. Conf. Multi-Material Micro Manufacture (2011): 149-155.

Koch, J., Feldmann, I., Jakubowski, N., and Niemax, K. (2002). Elemental Composition of Laser Ablation Aerosol Particles Deposited in the Transport Tube to an ICP. Spectrochim. Acta B. 57: 975-985.

Kong, L., Zhang, P., Setlow, P. and Li, Y. (2011). Multifocus Confocal Raman Microspectroscopy for Rapid Single-particle Analysis. J. Biomed. Opt. 16 (12) (December): 120503.

Kreyling, W.G., Semmler-Behnke, M. and Möller, W. (2006). Health Implications of Nanoparticles. J. Nanopart. Res. 8 (5) (October 7): 543-562.

Krueger, B. J., Grassian V.H., Iedema, M.J., Cowlin, J.P. and Laskin, A. (2003). Probing Heterogeneous Chemistry of Individual Atmospheric Particles Using Scanning Electron Microscopy and Energy-dispersive X-ray Analysis. Anal. Chem. 75 (19): 5170-5179. 
Kuhlbusch, T.A.J., Asbach, C., Fissan, H., Göhler, D. and Stintz, M. (2011). Nanoparticle Exposure at Nanotechnology Workplaces: a Review. Part. Fibre Toxicol. 8 (1) (January): 22 .

Laskin, A., Iedema, M.J. and Cowin, J.P. (2002). Quantitative Time-resolved Monitoring of Nitrate Formation in Sea Salt Particles Using a CCSEM/EDX Single Particle Analysis. Environ. Sci. Technol. 36 (23) (December 1): 4948-55.

Laskin, J., Laskin, A., and Nizkorodov, S.A. (2013). New Mass Spectrometry Techniques for Studying Physical Chemistry of Atmospheric Heterogeneous Processes. Int. Rev. Phys. Chem. 32 (1) (March): 128-170.

Lee, A.KY. and Chan, C.K. (2007). Single Particle Raman Spectroscopy for Investigating Atmospheric Heterogeneous Reactions of Organic Aerosols. Atmos. Environ. 41 (22) (July): 4611-4621.

Ling, L. and Li, Y. (2013). Measurement of Raman Spectra of Single Airborne Absorbing Particles Trapped by a Single Laser Beam. Opt. Lett. 38 (4) (February 15): 416-8.

Liu, Y., Yang, Z., Desyaterik, Y., Gassman, P.L., Wang, H., and Laskin, A. (2008). Hygroscopic Behavior of Substrate-Deposited Particles Studied by micro-FT-IR Spectroscopy and Complementary Methods of Particle Analysis. Anal. Chem. 80 (1148): 633-642.

Liu, Y., and Laskin, A. (2009). Hygroscopic Properties of $\mathrm{CH}_{3} \mathrm{SO}_{3} \mathrm{NA}, \mathrm{CH}_{3} \mathrm{SO}_{3} \mathrm{NH}_{4}$, $\left(\mathrm{CH}_{3} \mathrm{SO}_{3}\right)_{2} \mathrm{Mg}$, and $\left(\mathrm{CH}_{3} \mathrm{SO}_{3}\right)_{2} \mathrm{Ca}$ Particles Studied by micro-FTIR Spectroscopy. J. Phys. Chem. A 113: 1531-1538.

Matti Maricq, M. (2007). Chemical characterization of particulate emissions from diesel engines: A review, 38, 1079-1118.

Matthäus, C., Boydston-White, S., Miljkovi, M., Romeo, M., and Diem, M. (2006). Raman and infrared microspectral imaging of mitotic cells. Appl. Spectrosc. 60 (1): 1-8. 
Maynard, A. D. (2000). Overview of Methods for Analysing Single Ultrafine Particles.

Philosophical Transactions: Mathematical, Physical and Engineering Sciences, $358(1775), 2593-2610$.

Maynard, A.D. and Kuempel, E.D. (2005). Airborne Nanostructured Particles and Occupational Health. J. Nanopart. Res. 7 (6) (December): 587-614.

Maynard, A.D. and Aitken, R.J. (2007). Assessing Exposure to Airborne Nanomaterials: Current Abilities and Future Requirements. Nanotoxicology 1 (1) (March): 26-41.

McMurry, P. H. (2000). A review of atmospheric aerosol measurements. Atmospheric Environment, 34(12-14), 1959-1999.

Menzel, N., Schramel, P. and Wittmaack, K. (2002). Elemental Composition of Aerosol Particulate Matter Collected on Membrane Filters: A Comparison of Results by PIXE and ICP-AES. Nucl. Instrum. Meth. B. 189: 94-99.

Mertes, S., Dippel, B. and Schwarzenböck, A. (2004). Quantification of Graphitic Carbon in Atmospheric Aerosol Particles by Raman Spectroscopy and First Application for the Determination of Mass Absorption Efficiencies. J. Aerosol Sci. 35 (3) (March): 347-361.

Meyer, D.E., Curran, M.A. and Gonzalez, M.A. (2009). An Examination of Existing Data for the Industrial Manufacture and Use of Nanocomponents and Their Role in the Life Cycle Impact of Nanoproducts. Environ. Sci. Technol. 43 (5): 1256 - 1263.

Mouli, P.C., Mohan, S.V., Balaram, V., Kumar, M.P. and Reddy, S.J. (2006). A Study on Trace Elemental Composition of Atmospheric Aerosols at a Semi-arid Urban Site Using ICP-MS Technique. Atmos. Environ. 40: 136-146.

Nelson, M.P., Zugates, C.T., Treado, P.J., Casuccio, G.S., Exline, D.L. and Schlaegle,S.F. (2001). Combining Raman Chemical Imaging and Scanning Electron Microscopy to Characterize Ambient Fine Particulate Matter. Aerosol Sci. Tech. 34 (1): 108-117.

Nizkorodov, S.A., Laskin, J. and Laskin, A. (2011). Molecular Chemistry of Organic Aerosols Through the Application of High Resolution Mass Spectrometry. Phys. Chem. Chem. Phys.: PCCP 13 (9) (March 7): 3612-29. 
O’Brien, R.E., Laskin, A., Laskin, J., Liu, S., Weber, R., Russell, L.M. and Goldstein, A.H. (2013). Molecular Characterization of Organic Aerosol Using Nanospray

Desorption/Electrospray Ionization Mass Spectrometry: CalNex 2010 Field Study. Atmos. Environ. 68 (April): 265-272.

Oberdörster, G., Maynard, A., Donaldson, K., Castranova, V., Fitzpatrick, J., Ausman, K., Carter, J., Karn, B., Kreyling, W., Lai, D., Olin, S., Monteiro-Riviere, N., Warheit, D. and Yang, H. (2005). Principles for Characterizing the Potential Human Health Effects from Exposure to Nanomaterials: Elements of a Screening Strategy. Part. Fibre Toxicol. 2 (October 6): 8.

Offroy, M., Moreau, M., Sobanska, S., Milanfar, P., \& Duponchel, L. (2015). Pushing back the limits of Raman imaging by coupling super-resolution and chemometrics for aerosols characterization. Scientific Reports, 5 (July), 12303.

Ono-Ogasawara, M., Serita, F. and Takaya, M. (2009). Distinguishing Nanomaterial Particles from Background Airborne Particulate Matter for Quantitative Exposure Assessment. $J$. Nanopart. Res. 11 (7): 1651-1659.

Pope, C.A. III, and Dockery, D.W. (2006). Health Effects of Fine Particulate Air Pollution: Lines That Connect. J. Air Waste Manage. (April 2013): 37-41.

Prather, K.A., Nordmeyer, T. and Salt, K. (1994). Real-time Characterization of Individual Aerosol Particles Using Time-of-flight Mass Spectrometry. Anal. Chem. 66 (9) (May): $1403-1407$.

Rosen, H, and Novakov, T. (1977). Raman Scattering and the Characterisation of Atmospheric Aerosol Particles. Nature 266 (21 April 1977): 708-710.

Ryu, J., and Ro, C.-U. (2009). Attenuated Total Reflectance FT-IR Imaging and Quantitative Energy Dispersive-electron Probe X-ray Microanalysis Techniques for Single Particle Analysis Of Atmospheric Aerosol Particles. Anal. Chem. 81 (16): 6695-6707.

SCCS (Scientific Committee on Consumer Safety), Opinion on $\mathrm{ZnO}$ (nano form), 18 September 2012. 
Schwarzmeier, K., Knauer, M., Ivleva, N.P., Niessner, R., and Haisch, C. (2013). Bioaerosol Analysis Based on a Label-free Microarray Readout Method Using Surface-enhanced Raman Scattering. Anal. Bioanal. Chem. 405 (16) (June): 5387-92.

Schweiger, G. (1990). Raman Scattering on Single Aerosol Particles and on Flowing Aerosols: a Review. J. Aerosol Sci. 21 (4): 483-509.

Simeonova, P.P. and Erdely, A. (2009) Engineered Nanoparticle Respiratory Exposure and Potential Risks for Cardiovascular Toxicity: Predictive Tests and Biomarkers. Inhal. Toxicol. 21 Suppl 1, no. April (July 2009): 68-73.

Smijs, T.G., and Pavel, S. (2011). Titanium Dioxide and Zinc Oxide Nanoparticles in Sunscreens: Focus on Their Safety and Effectiveness. Nan. Sci. Appl. 95-112.

Sobanska, S., Falgayrac, G., Laureyns, J. and Brémard, C. (2006). Chemistry at Level of Individual Aerosol Particle Using Multivariate Curve Resolution of Confocal Raman Image. Spectrochim. Acta A. 64 (5) (August): 1102-9.

Sobanska, S., Hwang, H., Choël, M., Jung, H.-J., Eom, H.-J., Kim, H., Barbillat, J. and Ro, C.-U. (2012). Investigation of the Chemical Mixing State of Individual Asian Dust Particles by the Combined Use of Electron Probe X-ray Microanalysis and Raman Microspectrometry. Anal. Chem. 84 (7) (April 3): 3145-54.

Sobanska, S., Falgayrac, G., Rimetz-Planchon, J., Perdrix, E., Brémard, C., and Barbillat, J. (2014). "Resolving the internal structure of individual atmospheric aerosol particle by the combination of Atomic Force Microscopy, ESEM-EDX, Raman and ToF-SIMS imaging". Microchemical Journal, 114(May), 89-98.

Song, Y.-C., Ryu, J., Malek, M.A., Jung, H.-J. and Ro, C.-U. (2010). Chemical Speciation of Individual Airborne Particles by the Combined Use of Quantitative Energy-Dispersive Electron Probe X-ray Microanalysis and Attenuated Total Refelction Fourier TransformInfrared Imaging Techniques. Anal. Chem. 82 (19): 7987-7998.

Song, Y.-C., Eom, H.-J., Jung, H.-J., Malek, M.A., Kim, H.K., Geng, H. and Ro, C.-U. (2013). Investigation of Aged Asian Dust Particles by the Combined Use of Quantitative ED-EPMA and ATR-FTIR Imaging. Atmos. Chem. Phys. 13 (6) (March 27): 3463-3480. 
Stefaniak, E.A., Worobiec, A., Potgieter-Vermaak, S., Alsecz, A., Török, S. and Grieken, R.V. (2006). Molecular and Elemental Characterisation of Mineral Particles by Means of Parallel micro-Raman Spectrometry and Scanning Electron Microscopy/Energy Dispersive X-ray Analysis. Spectrochim. Acta B. 61 (7) (July): 824-830.

Tripathi, A., Jabbour, R.E., Guicheteau, J.A., Christesen, S.D., Emge, D.K., Fountain, A.W., Bottiger, J.R., Emmons, E.D. and Snyder, A.P. (2009). Bioaerosol Analysis with Raman Chemical Imaging Microspectroscopy. Anal. Chem. 81 (16) (August 15): 6981-90.

Vandebriel, R.J., and De Jong, W.H. (2012). A Review of Mammalian Toxicity of ZnO Nanoparticles. Nan. Sci. Appl. 5 (2012): 61-71.

Vehring, R. (1998). Linear Raman Spectroscopy on Aqueous Aerosols: Influence of Nonlinear Effects on Detection Limits. J. Aerosol Sci. 29 (1-2) (January): 65-79.

Vehring, R., Aardahl, C.L., Schweiger, G. and Davis, E.J. (1998). The Characterization of Fine Particles Originating from an Uncharged Aerosol: Size Dependence and Detection Limits for Raman Analysis. J. Aerosol Sci. 29 (9) (October): 1045-1061.

Worobiec, A., Potgieter-Vermaak, S., Brooker, A., Darchuk, L., Stefaniak, E. and Grieken, R.V. (2010). Interfaced SEM/EDX and micro-Raman Spectrometry for Characterisation of Heterogeneous Environmental Particles - Fundamental and Practical Challenges. Microchem. J. 94 (1) (January): 65-72.

Yang, W., Peters, J.I. and Williams, R.O. (2008). Inhaled Nanoparticles-A Current Review. Int. J. Pharm. 356 (1-2): 239-4. 